Products and Services In Practice is provided to readers using text and images from the manufacturer, supplier or distributor and does not imply endorsement by $B D J$ In Practice. Normal and prudent research should be exercised before purchase or use of any product mentioned.

Please send product and services news through to David Westgarth, BDJ In Practice via: David.Westgarth@bda.org

\section{Light the beacon}

As patient expectations of dental implants continue to increase, it is essential practitioners implement solutions that can help improve the efficacy of treatment. That's why W\&H offers the new Osstell Beacon handheld device, which is an excellent diagnostic tool designed to complement your digital workflow.

Using proprietary and evidence-based Resonance Frequency Analysis (RFA) technology, this intuitive device enables clinicians to assess osseointegration by identifying the best possible time to load an implant - all in a matter of seconds.

The Osstell Beacon offers an efficient, accurate, and non-invasive way of determining implant stability based on qualifiable data, thus enhancing osseointegration and the healing process.

This ensures clinicians are able to improve the quality of treatment by achieving more predictable outcomes.

To find out more visit www.wh.com/ en_uk, call 01727874990 or email office. uk@wh.com.
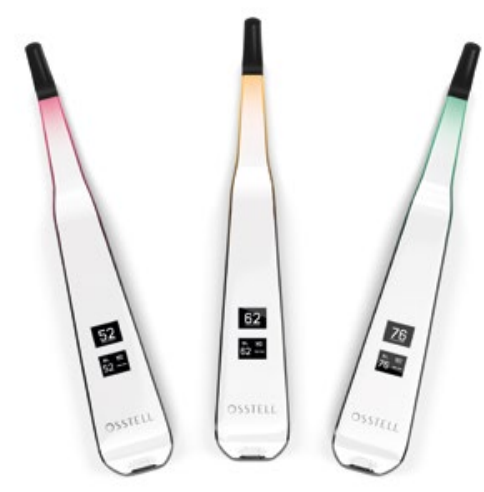

\section{Cleaning products that go the extra mile}

Effective decontamination protocols and cleaning regimes are the key to preventing the spread of illnesses in aesthetic settings.

But are your cleaning products up to scratch? Stop pathogens in their tracks by using the Steri-7 Xtra range of disinfectants from Initial Medical.

Able to deactivate $99.9999 \%$ of all pathogens including viruses, yeasts, spores, bacteria and fungi, these multi-purpose cleaners can be used around the whole of your salon, clinic or studio, providing effective defence against the spread of diseases. They also form a barrier that prevents pathogens recolonising for up to 72 hours after application.

Find out more by contacting Initial Medical on 08708504045 or visiting www. initial.co.uk/medical.

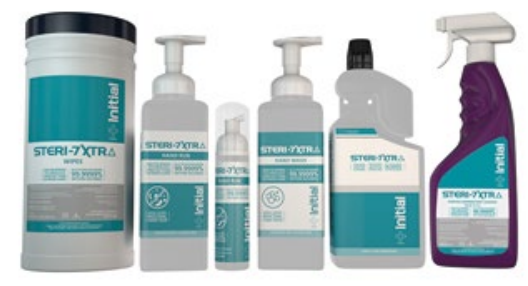

\section{Perfect preparation}

In order to cleanse assiduously before endodontic therapy, the canals must be enlarged and shaped properly.

Endodontic practitioners should try HyFlex EDM NiTi files, available from COLTENE.

HyFlex EDM NiTi files are your tools for perfect preparation. Stronger, up to $700 \%$ more fracture resistant, yet flexible too you will find that fewer files are needed for perfect preparation. Crucially, the root canal system will remain uncompromised, because the files follow the anatomy, reducing the risk of injury and damage.

COLTENE is committed to innovation; to improve workflow and give endodontic specialists the tools they need for excellent, stable results. To find out more visit www. coltene.com, email info.uk@coltene.com or call 01444235486.

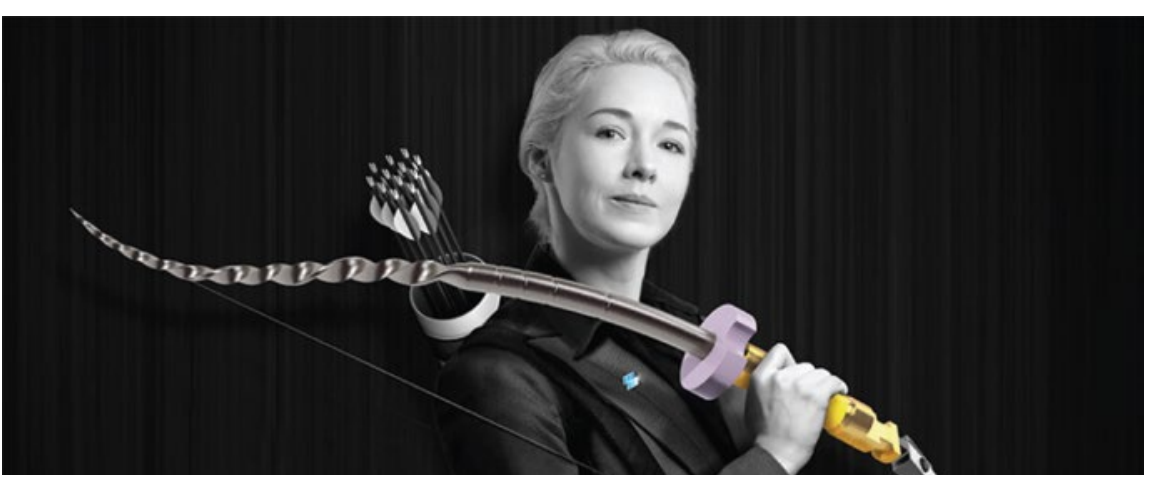

